\title{
The Substructure of the Suprachiasmatic Nucleus: Similarities between Nocturnal and Diurnal Spiny Mice
}

\author{
Rotem Cohen $^{\mathrm{a}}$ Noga Kronfeld-Schor ${ }^{\mathrm{a}}$ Chidambaram Ramanathan ${ }^{\mathrm{b}}$ \\ Anna Baumgras $^{\text {b }}$ Laura Smale ${ }^{b}$ \\ a Department of Zoology, Tel Aviv University, Tel Aviv, Israel; 'b Department of Psychology, \\ Department of Zoology and Neuroscience Program, Michigan State University, East Lansing, Mich., USA
}

\section{Key Words}

Suprachiasmatic nucleus - Nocturnal · Diurnal · Acomys •

Serotonin - Vasopressin - Vasoactive intestinal polypeptide •

Calbindin $\cdot$ Gastrin-releasing peptide $\cdot$ Neuropeptide $Y$

\section{Abstract}

Evolutionary transitions between nocturnal and diurnal patterns of adaptation to the day-night cycle must have involved fundamental changes in the neural mechanisms that coordinate the daily patterning of activity, but little is known about how these mechanisms differ. One reason is that information on these systems in very closely related diurnal and nocturnal species is lacking. In this study, we characterize the suprachiasmatic nucleus $(\mathrm{SCN})$, the primary brain structure involved in the generation and coordination of circadian rhythms, in two members of the genus Acomys with very different activity patterns, Acomys russatus (the golden spiny mouse, diurnal) and Acomys cahirinus (the common spiny mouse, nocturnal). Immunohistochemical techniques were used to label cell bodies containing vasoactive intestinal polypeptide (VIP), vasopressin (VP), gastrin-releasing peptide (GRP) and calbindin (CalB) in the $\mathrm{SCN}$, as well as two sets of inputs to it, those containing serotonin (5-HT) and neuropeptide $\mathrm{Y}(\mathrm{NPY})$, respectively. All were present in the $\mathrm{SCN}$ of both species and no differences between them were seen. On the basis of neuronal phenotype, the SCN was organized into three basic regions that contained VIP-immunoreactive (-ir), CalB-ir and VP-ir cells, in the ventral, middle and dorsal SCN, respectively. In the rostral SCN, GRP-ir cells were in both the VIP and the CalB cell regions, and in the caudal area they were distributed across a portion of each of the other three regions. Fibers containing NPY-ir and serotonin (5-HT)-ir were most concentrated in the areas containing VIP-ir and CalB-ir cells, respectively. The details of the spatial relationships among the labeled cells and fibers seen here are discussed in relation to different approaches investigators have taken to characterize the SCN more generally.

Copyright $\odot 2010$ S. Karger AG, Basel

\section{Introduction}

Over the course of evolution, diurnal and nocturnal species have diverged with respect to mechanisms that coordinate the daily patterning of many features of their behavior and physiology. The primary drive for these rhythms comes from a circadian timekeeping system that

\section{KARGER}

() 2010 S. Karger AG, Basel

Fax +41613061234

E-Mail karger@karger.ch

www.karger.com
Accessible online at: www.karger.com/bbe
Rotem Cohen

Department of Zoology, Tel Aviv University

IL-69978 Tel Aviv (Israel)

Tel. +972 3640 5740, Fax +972 36409403

E-Mail rotemc@tauex.tau.ac.il,cohenrot@gmail.com 
can be described at the simplest level as consisting in mammals of three central components [Klein et al., 1991]. These include the suprachiasmatic nuclei (SCN) which contain the primary self-sustaining oscillators that generate and coordinate the rhythms, inputs through which photic and non-photic signals entrain these rhythms to $24 \mathrm{~h}$ cycles in the environment, and outputs that distribute rhythmic signals from the SCN to brain regions that more directly regulate behavior and physiology. Although this circadian system enables animals to maintain internal synchrony and to anticipate rhythmic changes in the environment, processes referred to as masking can modulate these rhythms on a daily basis by more directly influencing the variables in question [e.g., activity, body temperature; Mrosovsky, 1999]. Masking does not involve anticipation of a change in the environment, but rather an immediate response to such changes. Exposure to darkness during the day, for example, can stimulate an abrupt increase in activity in a nocturnal animal and a decrease in a diurnal one, and these effects are not brought about via changes in the endogenous circadian timekeeping system. The effect of a masking stimulus on activity ends immediately after it is removed. Both the circadian regulation of activity and masking differ in day- and night-active species. In diurnal species the circadian system drives sleep during the night and wakefulness during the day, whereas masking by light at night directly stimulates activity, and by darkness during the day decreases it. Both systems have the opposite effects in nocturnal species [Mrosovsky, 1999; Hagenauer and Lee, 2008].

The SCN are bilateral collections of tightly packed cells located in the anterior hypothalamus dorsal to the optic chiasm, one on each side of the third ventricle [Klein et al., 1991]. They contain multiple populations of cells that differ with respect to their distribution and function, but at the simplest level, the SCN have been described by Abrahamson and Moore [2001] as containing 'shell' and 'core' regions on the basis of differences in inputs as well as the phenotypes of cells within. The term 'core' refers to an area of the SCN, typically ventral, which contains cell bodies with vasoactive intestinal polypeptide (VIP) and gastrin-releasing peptide (GRP) and receives input from the retina, the raphe nucleus and the intergeniculate leaflet (IGL) of the thalamus. The 'shell' refers to an area of the SCN where cells containing vasopressin (VP) are present [Abrahamson and Moore, 2001; Moore et al., 2002]. Although the SCN of almost all mammals contain these three peptides and inputs, respectively, the general bi-partite conceptualization of the SCN has been criticized recently by Morin et al. [2006] for oversimplifying the basic structure of the nucleus within any given species and for overlooking important differences among species. There is cross-species variability, for example, with respect to the presence or absence of a number of peptides contained within SCN cells as well as the distributions and the degree of overlap among these phenotypically distinct populations of cells [Goel et al., 1999; Morin et al., 2006]. The patterns of inputs to the nucleus also vary from species to species and do not always map onto core and shell regions as defined by cell phenotype [Cavalcante et al., 2002; Morin et al., 2006; Pinato et al., 2007]. Of particular note is that in some species, such as hamsters and mice, what has been called the core actually consists of different, though partially overlapping, subregions associated with cells of different phenotypes [Morin et al., 2006] and functions [Antle and Silver, 2005]. For example, in the SCN of hamsters CalB and substance $\mathrm{P}$ are concentrated in a central region of the caudal portion of the core which contains relatively few cells with either VIP or VP [Morin et al., 1992; Silver et al., 1996]; a similar sub-region of the SCN is demarcated by the presence of met-enkephalin in the ground squirrel SCN [Smale et al., 1991]. The significance of the species differences in SCN organization is unknown, however, and those that have been identified have not been associated with whether an animal is nocturnal or diurnal.

As with SCN anatomy, many indicators of SCN function appear to be the same across species with very different activity patterns. This is the case for rhythms of metabolic activity, expression of genes that are central to the core molecular oscillator and expression of genes that encode proteins and peptides representing several output systems [reviewed in Smale et al., 2008]. Recent data suggest that although production of one SCN output signal, $\mathrm{VP}$, is the same, responses to it can be reversed in diurnal and nocturnal species [Kalsbeek et al., 2008]; however, there are also some features of SCN function that can differ in some day- and night-active species. These include patterns of expression of immediate early genes [Krajnak et al., 1997], rhythms in neuronal firing rates [Jiao et al., 1999], temporal patterns of expression in TGF $\alpha$ [Tournier et al., 2007], and effects of GABA agonists and antagonists on rhythm phase [Novak et al., 2004]. It is not yet known whether or how these might ordinarily contribute to differences in patterns of overt rhythmicity.

Most of what is known about neural substrates underlying rhythms comes from research on mammals that are quite stable with respect to the temporal niche they occupy. Some animals, however, are very plastic and can be diurnal in some environmental conditions and nocturnal 
in others [Kronfeld-Schor and Dayan, 2003, 2008]. Examples include microtine rodents that are diurnal in winter and nocturnal in the summer [Rowsemitt et al., 1982] and cotton rats in which patterns differ across individuals and change over time [Camerson and Spencer, 1981; Johnston and Zucker, 1983; Hoogenboom et al., 1984; Hagenauer and Lee, 2008]. Plasticity can be promoted by changes in masking or in circadian mechanisms [Mrosovsky and Hattar, 2005]. An example of the former was recently reported for Nile grass rats in which a change from a day- to a night-active pattern was associated with a reversal in masking responses to light [Redlin and Mrosovsky, 2004]. Relatively little is known about the neural substrates underlying masking and a number of brain regions might play a role [Redlin, 2001], including the SCN [Li et al., 2005]. Nothing is known about the neural mechanisms responsible for differences in masking seen in animals with day- and night-active patterns of rhythmicity.

One excellent animal model with which such issues could be addressed is the golden spiny mouse (Acomys russatus, Muridae), a diurnal species that is capable of adjusting to a nocturnal pattern in certain circumstances. These animals have a limited distribution in rocky deserts in northeastern Egypt, southern Israel and Jordan [Mendelson and Yom-Tov, 1999] and in most, but not all [Scott and Dunstone, 2000] of their natural habitat they are diurnal [Shkolnik, 1966, 1971; Haim and Borut, 1975; Kronfeld-Schor et al., 1994, 2001a; Elvert et al., 1999]; however, when they are transferred to the laboratory from their natural habitat at Ein Gedi, where they are most active during the day, patterns of all individuals change abruptly, with some becoming nocturnal and others becoming active both day and night [KronfeldSchor et al., 2001a]. This immediate change also occurs when the animals are transferred from the field into constant darkness (DD) in the laboratory [Levy et al., 2007]. These patterns raise the possibility that golden spiny mice have a circadian timekeeping system that is highly plastic and can drive daytime behavior in some conditions (e.g., the field) and nighttime activity in others (e.g., the lab). An alternative explanation is that the circadian system does not change, but activity is masked in such a way that one pattern is evident in the field and another in the lab. For example, the laboratory conditions might reveal a fundamental circadian drive for nocturnality that is ordinarily masked in most of the natural habitat of these animals [Kronfeld-Schor et al., 2001a; Cohen and Kronfeld-Schor, 2006; Levy et al., 2007]. This hypothesis is supported by data from controlled field experiments showing that when they have the chance (e.g., in the absence of a competitor, Acomys cahirinus), golden spiny mice are active both during day and at night [Shkolnik, 1971; Gutman and Dayan, 2005; Kronfeld-Schor and Dayan, 2008]. We have suggested previously that golden spiny mice are in an intermediate evolutionary state representative of what can occur during evolutionary transitions from nocturnal to diurnal patterns of adaptation to the environment [Kronfeld-Schor and Dayan, 2008]. This possibility is supported by a mosaic pattern of other adaptations some of which support daytime and others nighttime activity. For example, their dark skin pigmentation [Chaplin, 2004; Jablonski, 2004] and high concentration of ascorbic acid in the eyes, which enables them to withstand intense solar radiation [Koskela et al., 1989], are typical adaptations to daytime activity. On the other hand, their retinal structure is like that of nocturnal mammals [Kronfeld-Schor et al., 2001b], as is their capacity for non-shivering thermogenesis which helps support activity when ambient temperatures are lowest [Kronfeld-Schor et al., 2000, 2001c].

The predominantly diurnal but highly flexible golden spiny mouse has a congener, Acomys cahirinus, the common spiny mouse, which is strictly nocturnal throughout its range as well as in the laboratory [Kronfeld-Schor et al., 1994; Elvert et al., 1999; Weber and Hohn, 2005]. The existence of these two very closely related species provides a unique opportunity to examine the mechanisms that might be responsible for inter-specific variation in activity patterns and in the level of commitment an animal has to a given temporal niche. Our long-term goal is to use the golden spiny mouse as an alternative animal model for the study of interactions between masking and circadian systems and how these might determine the extent to which an animal is active during the day or night. One possibility is that processes within the SCN are responsible, and another is that the SCN is the same and the differences emerge from structures or functions of other brain regions involved in regulation of daily rhythms. A third possibility is that differences in temporal organization of day and night-active animals emerge from processes operating both within and beyond the SCN. In the current study we begin to evaluate these alternatives by describing and comparing the basic organization of the SCN in golden and common spiny mice. Specifically, we used immunohistochemical techniques to examine the distributions of VIP, VP, GRP, CalB, NPY and serotonin $(5-\mathrm{HT})$ in the SCN of these two species. 


\section{Methods}

\section{Animals and Housing}

Animals were adult male and female golden and common spiny mice from our breeding colony at the I. Meir Segals Zoological Garden at Tel Aviv University. The source of the breeding colony is Ein Gedi, near the Dead Sea, Israel, where the two species coexist. The mice were individually housed in $38 \times 24 \times 13$ $\mathrm{cm}$ plastic cages, under controlled laboratory conditions of LD $12: 12$, and ambient temperature of $29^{\circ} \mathrm{C}$, with food (standard rodent chow) and water ad libitum. All procedures were conducted in accordance with and approved by the Institutional Animal Ethics Committee (L-02-45). All efforts were made to minimize the number of animals used and their discomfort.

\section{Perfusion and General Immunocytochemical Procedure}

At the time of perfusion, animals were given an overdose of isoflorane and perfused transcardially with $0.01 \mathrm{M}$ phosphatebuffered saline (PBS), pH 7.2, followed by $4 \%$ paraformaldehyde (Sigma, St. Louis, Mo., USA) in $0.1 \mathrm{M}$ phosphate buffer. Brains were post-fixed for $4 \mathrm{~h}$, transferred to $20 \%$ sucrose solution overnight, and then stored in cryoprotectant at $-20^{\circ} \mathrm{C}$ until sectioning. Brains were later returned to sucrose and sectioned coronally at $30 \mu \mathrm{m}$ on a freezing microtome.

Free-floating sections were rinsed in PBS, and then incubated in (i) 5\% normal serums in PBS with $10 \%$ Triton X-100, followed by (ii) primary antibody for either NPY, VIP VP, GRP, 5 HT or $\mathrm{CalB}$ (see below for details) on a rotator for $48 \mathrm{~h}$ at $4^{\circ} \mathrm{C}$. Tissue was then incubated in (iii) biotinylated secondary antibody, followed by (iv) avidin-biotin peroxidase complex (ABC Vectastain Kit; Vector Laboratories, Burlingame, Calif., USA). Protein was visualized by reacting with diaminobenzidine $(0.5 \mathrm{mg} / \mathrm{ml}$; Sigma) in Trizma buffer (Sigma). Sections were then mounted, dehydrated, and coverslipped with Permount.

Antibodies and sera used for each antigen were as follows. VP: (i) NGS, (ii) guinea-pig anti-VP (Peninsula Laboratories, Belmont, Calif., USA; 1:40,000), (iii) biotinylated goat anti-guineapig (Vector; 1:200). VIP: (i) NGS, (ii) guinea-pig anti-VIP (Peninsula Laboratories, Belmont, Calif., USA; 1:20,000), (iii) biotinylated goat anti-guinea-pig (Vector; 1:200). CalB: (i) NDS, (ii) mouse anti-CalB (Sigma; 1:20,000), (iii) biotinylated donkey anti-mouse (Jackson; 1:200). 5-HT: (i) NGS, (ii) rabbit anti-5-HT (Peninsula Laboratories, Belmont, Calif., USA; 1:50,000), (iii) biotinylated goat anti-rabbit (Vector; 1:200). NPY: (i) NGS, (ii) rabbit anti-NPY (Peninsula Laboratories, Belmont, Calif., USA; 1:20,000), (iii) biotinylated goat anti-rabbit (Vector; 1:200). GRP: (i) NGS, (ii) rabbit anti-GRP (Peninsula Laboratories, Belmont, Calif., USA; 1:10,000), (iii) biotinylated goat anti-rabbit (Vector; 1:200). Deletion controls were run in which primary antibodies were omitted but the rest of the procedures were the same as those used for experimental tissue. In all cases the control tissue processed without a primary antibody revealed no staining at all in either species, whereas tissue processed concurrently with primary antibodies was clearly stained for the antigen, in both species.

Data Analyses

Slides were examined and photomicrographs taken using a Zeiss light microscope (Axioskop 2 Plus; Carl Zeiss, Göttingen, Germany). Photographs of representative sections were taken with a digital camera (AxioCam MRc) attached to the micro- scope. Contrast and color balance were optimized using Zeiss AxioVision software (Carl Zeiss Vision). Figures were then assembled using Adobe Illustrator and Adobe Photoshop (Adobe Systems, San Jose, Calif., USA).

\section{Results}

\section{General}

The SCN of the golden and common spiny mouse were very similar with respect to the size and shape of the nucleus and the distribution of peptidergic cells and of serotonin and NPY fibers within it. In this paper we present photographs of the rostral, middle and caudal levels of the SCN of the golden spiny mouse (fig. 1,2, 5, 6), but only the mid-level SCN of the common spiny mouse (fig. 1, 3) to avoid unnecessary redundancy. Descriptions we provide below apply to the SCN of both species.

In cresyl violet-stained material the SCN appeared as discrete bilaterally symmetrical nuclei immediately dorsal to the caudal third of the optic chiasm in both the golden (fig. 1A-C) and the common (fig. 1D) spiny mice. Cells within the nucleus were smaller and more densely packed than in surrounding tissue. The distinction was less sharp along the dorsal border where some smaller cells in the peri-SCN area were interspersed amongst larger more diffusely distributed ones. In coronal sections the SCN had a teardrop shape that was expanded along the dorso-ventral axis in its caudal regions. At its rostral end, the third ventricle extended completely between the two SCN and in caudal regions it extended only between the most dorsal portions of the two nuclei which were thus in closer contact with each other. The optic chiasm was considerably thicker in both Acomys species compared to rodents more traditionally used in research (mice, rats and hamsters).

\section{Vasoactive Intestinal Polypeptide}

In both species, parvicellular VIP-ir neurons and fibers were present within the SCN (fig. 2, 3). In rostral sections these cells were seen in a somewhat narrow band that extended across the full medial-lateral extent of the nucleus and curved dorsally at both ends to form what looked like a cup lining the outer edges of the nucleus. In the most caudal sections, VIP-ir cells were concentrated in a more restricted region of the ventral SCN that did not extend all the way from its medial to lateral boundaries (fig. 2). Numerous parvicellular VIP-ir neurons were also embedded within the optic chiasm ventral to the SCN proper, separated from it by the dorsal portion of the optic chiasm; fibers from these VIP-ir cells extended dor- 

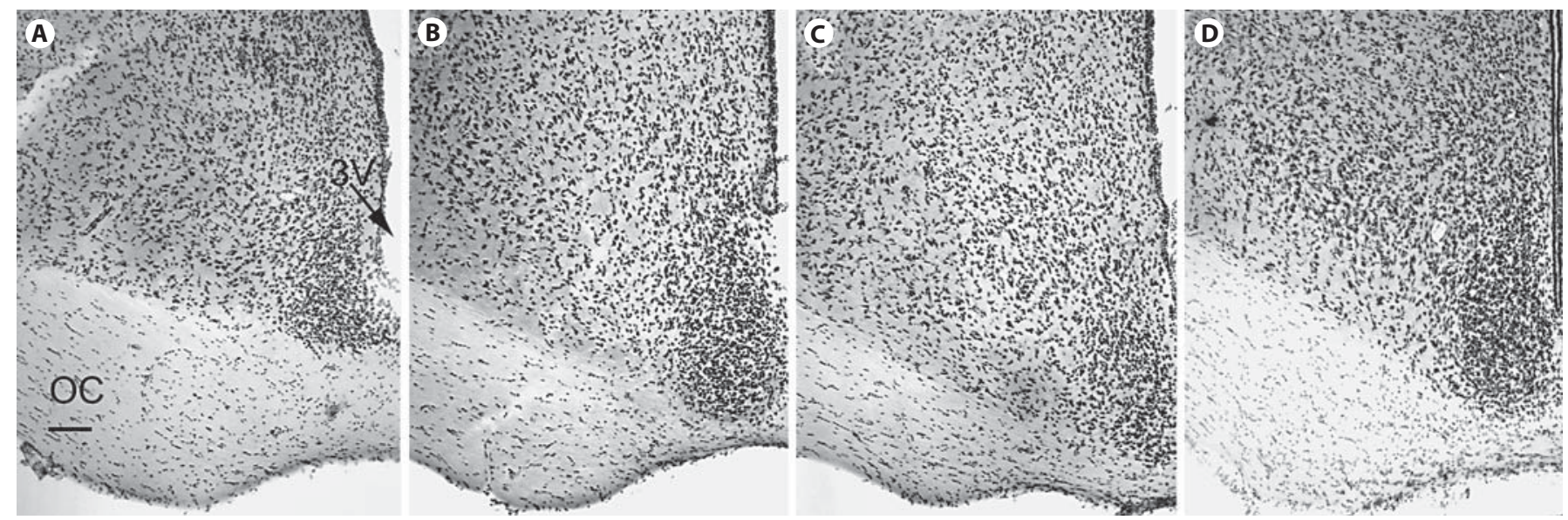

Fig. 1. A series of cresyl violet-stained coronal sections through the SCN of the golden spiny mouse (A-C) and common spiny mouse $(\mathbf{D})$ from rostral $(\mathbf{A})$ through caudal $(\mathbf{C})$ poles of the nucleus. $3 \mathrm{~V}=$ Third ventricle, $\mathrm{OC}=$ optic chiasm. Bar $=100$ microns.

Fig. 2. Sections stained for immunohistochemical detection of VIP (top row) and VP (bottom row) in the SCN of golden spiny mice. Rostral, middle and caudal sections are depicted from left to right, respectively. There is little overlap between the areas of the SCN containing VIP-ir and VP-ir cells. Areas containing neither peptide are evident in the center of the rostral and middle sections of the nucleus and in the centro-lateral region of the caudal portion of the nucleus. $3 \mathrm{~V}=$ Third ventricle, $\mathrm{OC}=$ optic chiasm. Bar $=100 \mathrm{mi}-$ crons.

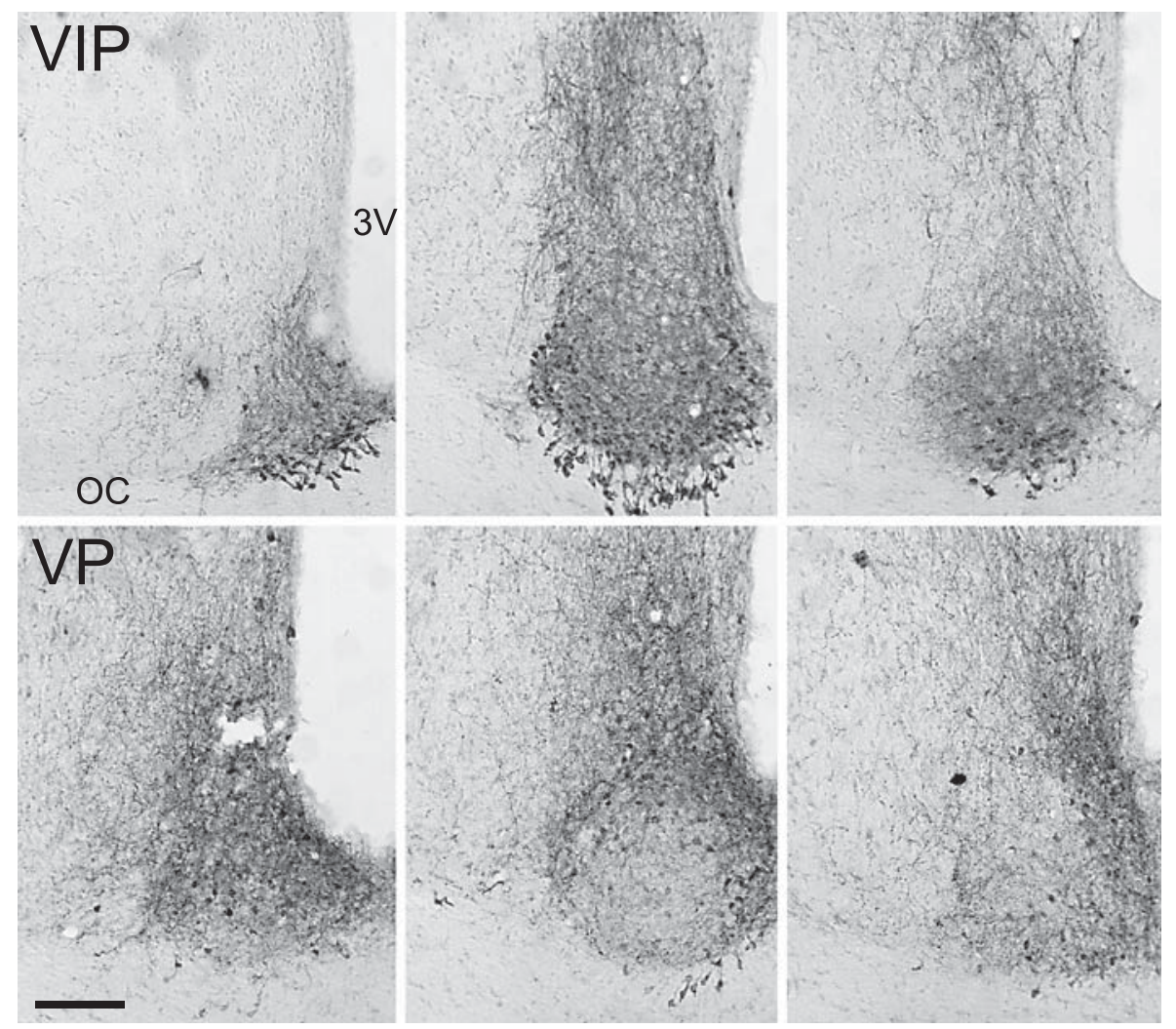

sally through the optic chiasm and into the SCN (fig. 2, 3). No VIP-stained cells were seen in other regions of the hypothalamus.

Most VIP-ir fibers emanating from the SCN were part of a single large tract emerging from the full extent of the medio-lateral axis of the nucleus into the sub-PVN zone (fig. 2-4). These were most evident in sections containing caudal regions of the nucleus, where they extended dorsally for a considerable distance (fig. 4A-C). VIP-ir fibers in this area were lined with boutons suggestive of an SCN 

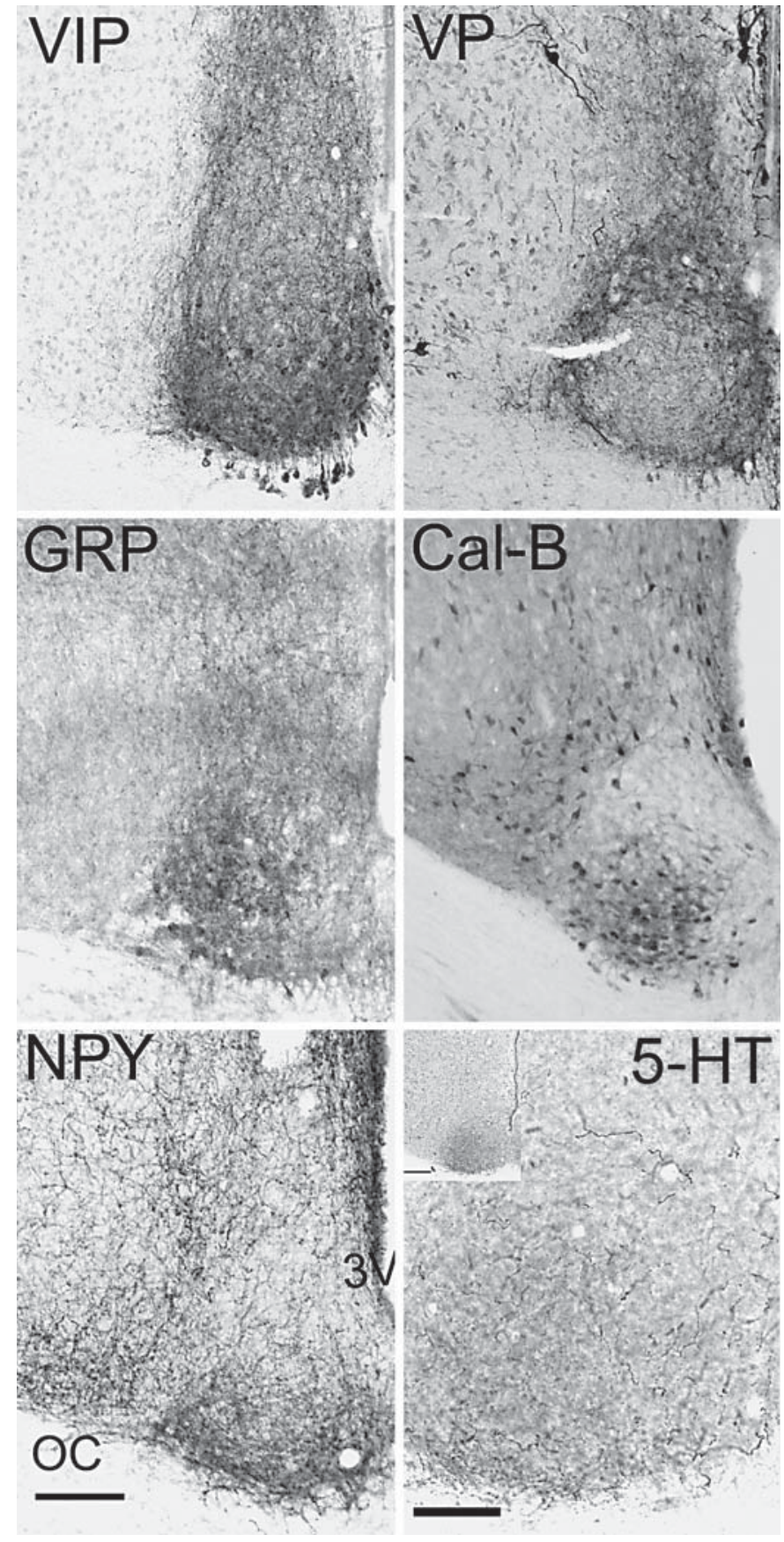

Fig. 3. Sections through the SCN (mid-SCN) of the common spiny mice that have been stained for immunohistochemical detection of VIP, VP, GRP, Cal-B, NPY and 5-HT. The bar in the lower left portion of the NPY photomicrograph indicates 100 microns in photos that depict VIP, VP, GRP, Cal-B and NPY. The larger photo of the 5-HT staining was taken at a higher magnification and the scale bar represents 50 microns. The insert in the upper left portion of the photograph of 5-HT staining shows the SCN at lower magnification in order to illustrate the distribution of the labeled fibers within the SCN in relation to the area around it; here the scale bar represents 100 microns. $3 \mathrm{~V}=$ Third ventricle, $\mathrm{OC}=$ optic chiasm. projection onto cells or fibers in the sub-PVN area. Labeled fibers that appeared to originate in the SCN also extended dorsally into the paraventricular nucleus of the hypothalamus (PVN; fig. 4D-F) and the paraventricular thalamus (PVT; fig. 4G-I). VIP-ir fibers were also apparent lateral to the SCN, adjacent to the optic chiasm and the supraoptic nucleus (SON) and rostral to the SCN where they were in the anteroventral periventricular area (AVPV; fig. 4J, L, N) and the medial preoptic nucleus (MPOA; fig. 4J, K, M). A dense plexus of labeled fibers was also seen in the bed nucleus of the stria terminalis (BNST), but these did not appear to originate in the SCN.

\section{Vasopressin}

Parvicellular VP-ir neurons and fibers in both species were present across the rostral-caudal extent of the SCN (fig. 2, 3). Within the mid to rostral SCN these cells were most concentrated in an arc that extended dorsally from the ventromedial region of the nucleus to its ventrolateral aspect; within this area they were slightly more concentrated dorso-medially. As was the case for VIP-ir cells, those containing VP-ir were embedded within the optic chiasm ventral to the SCN. These VP-ir cells were most evident ventral to the medial aspect of the SCN where their distribution appeared to overlap slightly with that of VIP-ir cells (fig. 2, 3). In the caudal SCN the distribution of VP-ir cells was somewhat more limited, as they did not extend into the dorso-lateral region of the nucleus. This dorso-lateral region also contained very few VIP neurons. Some large magnocellular VP-ir cells were present along the third ventricle immediately dorsal to the SCN (fig. 3), in the PVN and in the SON; in males, magnocellular VP-ir cells were also seen in a small cluster mid-way between these two nuclei and in the BNST (data not shown).

Large numbers of fine caliber VP-ir fibers were seen exiting the SCN from its medial region into the sub-PVN zone all along its rostro-caudal extent (fig. 2, 3). Within the sub-PVN zone these fibers diverged into a medial and a lateral pathway separated by a region with relatively few fibers. The larger of these two pathways was concentrated in the medial region of the sub-paraventricular area and the smaller was in a more lateral region. Both were somewhat more dense dorsal to the caudal than to the rostral portion of the nucleus. These fibers extended a considerable distance into the sub-PVNzone where somebranched in a direction lateral to it. As with VIP, some fine caliber VP-ir fibers fanned out from the SCN into the surrounding POA, some extended rostrally into the MPOA and 

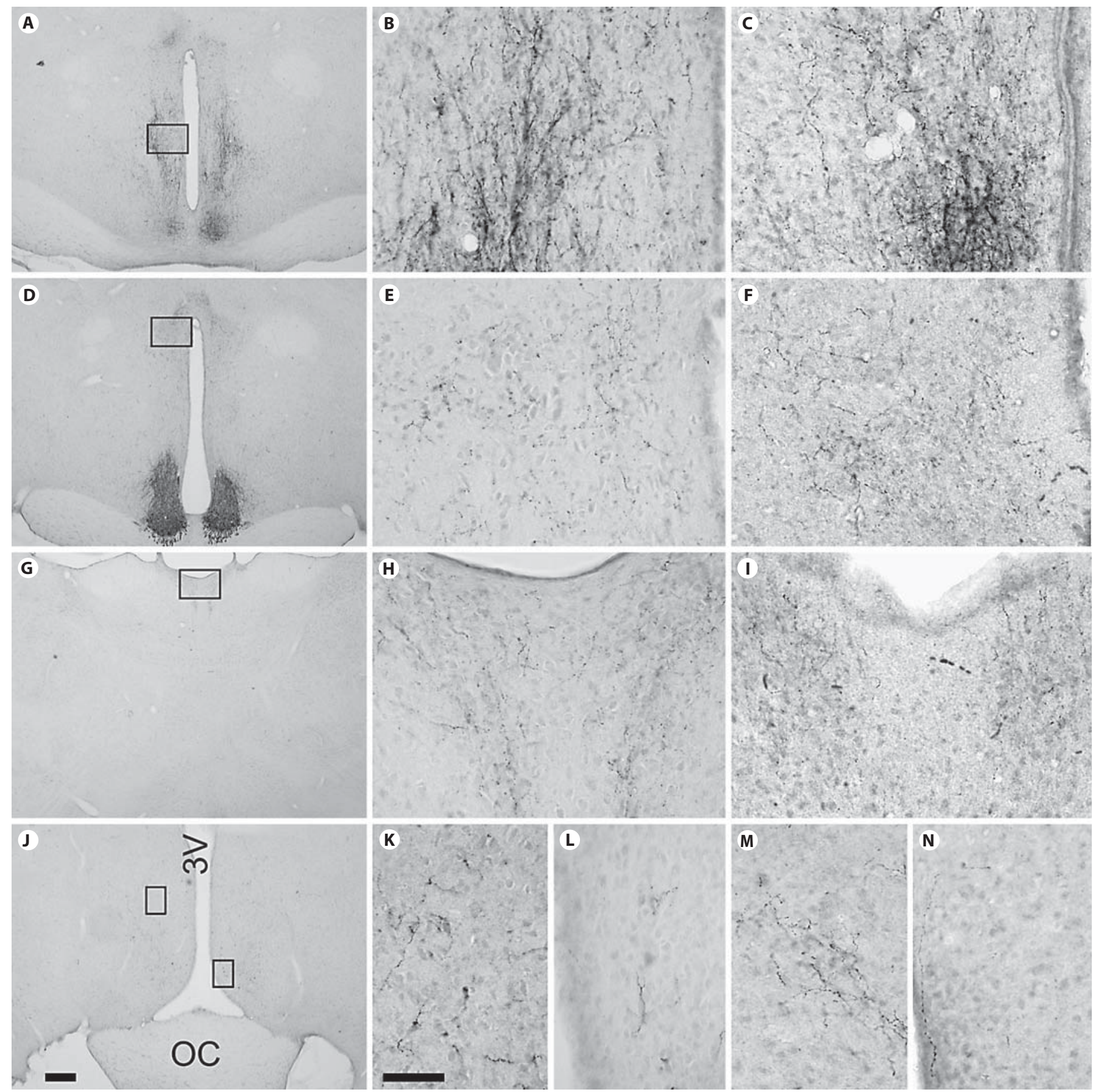

Fig. 4. Fibers containing VIP-ir in different regions of the rostral hypothalamus and in the thalamus of golden and common spiny mice. Fibers are present in the sub-PVN zone $(\mathbf{A}-\mathbf{C})$, the PVN (D-F), the PVT (G-I), the AVPV (medial box of $\mathbf{J} ; \mathbf{L}, \mathbf{N}$ ) and the POA (lateral box of $\mathbf{J} ; \mathbf{K}, \mathbf{M}$ ). Low magnification photomicrographs on the left (A, D, G, J) are of tissue from golden spiny mice; the scale bar in $\mathbf{J}$ represents 200 microns in these four photomi-

crographs. High magnification photomicrographs in the middle column $(\mathbf{B}, \mathbf{E}, \mathbf{H}, \mathbf{K}, \mathbf{L})$ depict tissue of golden spiny mice and those in the right column depict tissue of common spiny mice (C, F, I, $\mathbf{M}, \mathbf{N}$ ); the bar in $\mathbf{K}$ represents 50 microns in all of these high magnification photographs. $3 \mathrm{~V}=$ Third ventricle, $\mathrm{OC}=$ optic chiasm. 
Fig. 5. Sections through the SCN of golden spiny mice that have been stained for immunohistochemical detection of GRP (top row) and CalB (bottom row). Rostral, middle and caudal sections are depicted from left to right, respectively. There is little overlap between the areas of the SCN containing cells with CalB-ir seen here and those depicted in figure 2 with VIP-ir and VP-ir cells. 3V = Third ventricle, $\mathrm{OC}=\mathrm{op}-$ tic chiasm. Bar $=100$ microns.
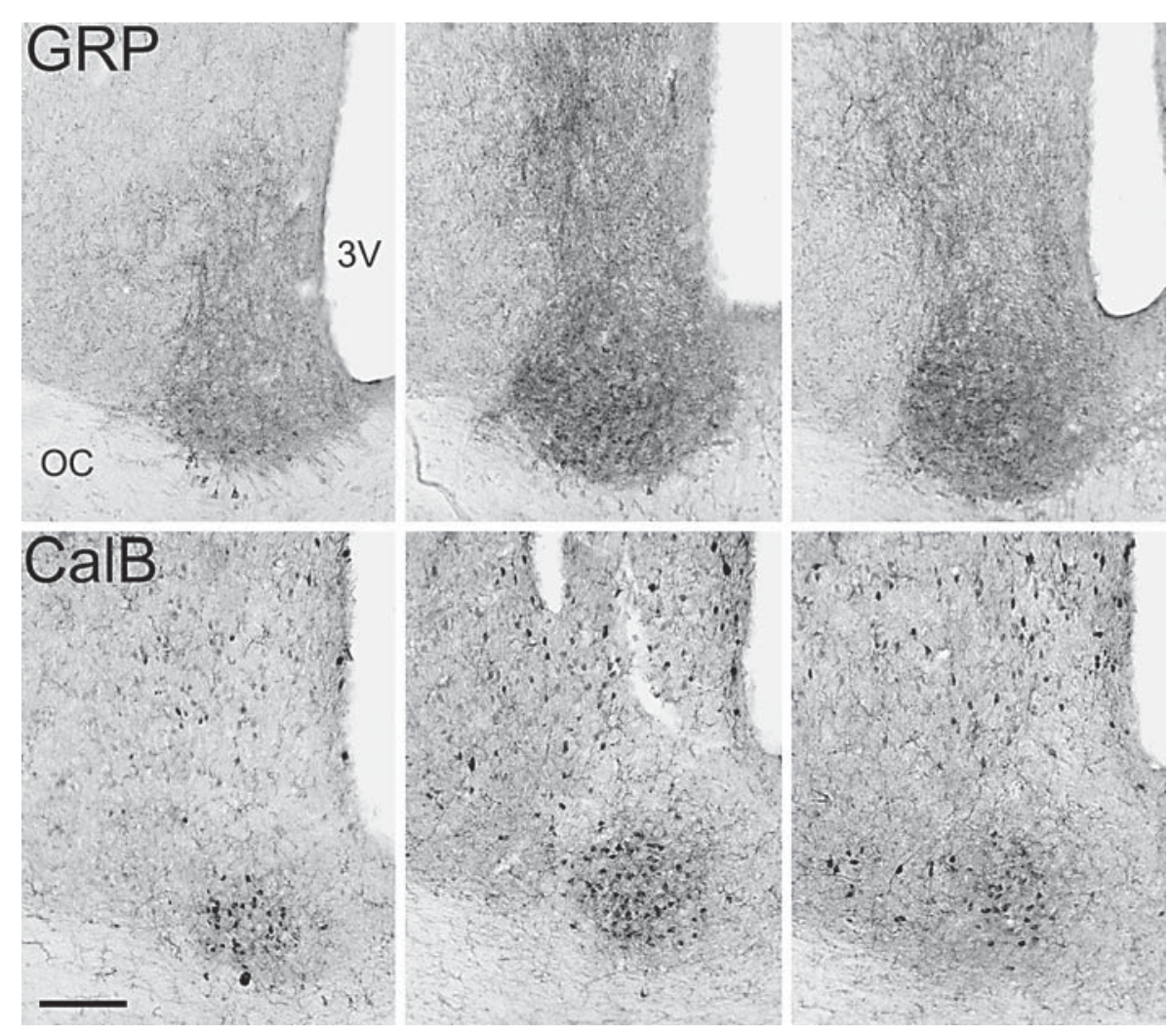

AVPV, and some were seen directed laterally to the SON. Fine caliber VP-ir fibers were also present in the PVN and PVT.

\section{Gastrin-Releasing Peptide}

In both species GRP-ir neurons and fibers were present within the SCN all along its rostal-caudal axis, although there were somewhat fewer of them than there were of cells containing VIP-ir and VP-ir. GRP-ir cells were also seen within the optic chiasm ventral to the SCN (fig. 3, 5). In sections through the rostral SCN, GRP-ir cells were most concentrated in the ventral portion of the nucleus, whereas in mid-level sections they were most dense in the ventro-lateral portion of the nucleus. In the caudal regions, GRP-ir cells extended dorsally into the area noted above where few VIP-ir or VP-ir cells were seen (fig. 5).

The major tract of GRP-ir fibers emanating from the $\mathrm{SCN}$ extended dorsally into the sub-PVN zone. In caudal sections, approximately 300-400 microns dorsal to the $\mathrm{SCN}$, some of these fibers branched out from the primary tract and curved in a lateral direction. Some fine caliber GRP fibers were also seen in the PVN and PVT.

\section{Calbindin}

Staining for CalB was seen in the SCN where it was primarily restricted to cell bodies, although in some cases it could be seen in processes as they emerged from the soma (fig. 3, 5). CalB-ir cells extended from rostral to caudal SCN but were most numerous at its mid-level (fig. 5). These cells were most heavily concentrated in what appeared as a somewhat spherical sub-nucleus within the mid to lateral area where, as noted above, few VIPir or VP-ir cells were seen (fig. 3, 5). At the rostral end of their distribution some CalB-ir cells were embedded in the optic chiasm. Labeled cells surrounded the SCN throughout its rostro-caudal extent and at the level of the mid and caudal SCN these cells appeared as an arc that extended dorsally and laterally from the SCN (fig. 5).

\section{Neuropeptide $Y$}

Large numbers of thick varicose NPY-ir fibers were present in the hypothalamic area surrounding the SCN all along its rostral-caudal axis (fig. 3, 6). Within the rostral SCN, NPY-ir fibers were sparse but in the mid and caudal regions a substantial plexus of fine caliber-labeled fibers was present (fig. 6). These fibers were most concen- 
Fig. 6. Sections through the SCN of the golden spiny mice that have been stained for immunohistochemical detection of NPY (top row) and 5-HT (bottom row). Rostral, middle and caudal sections are depicted from left to right, respectively. The bar in the lower left portion of the NPY photomicrograph indicates $100 \mathrm{mi}-$ crons in all three photographs in that row. The larger photographs of the 5-HT staining were taken at a higher magnification and the scale bar represents 50 microns. The inserts in the upper right portions of the photographs of 5-HT staining show the SCN at lower magnification in order to illustrate the distribution of the labeled fibers within the SCN in relation to the area around it; here the scale bar represents 100 microns. $3 \mathrm{~V}=$ Third ventricle, $\mathrm{OC}=$ optic chiasm.
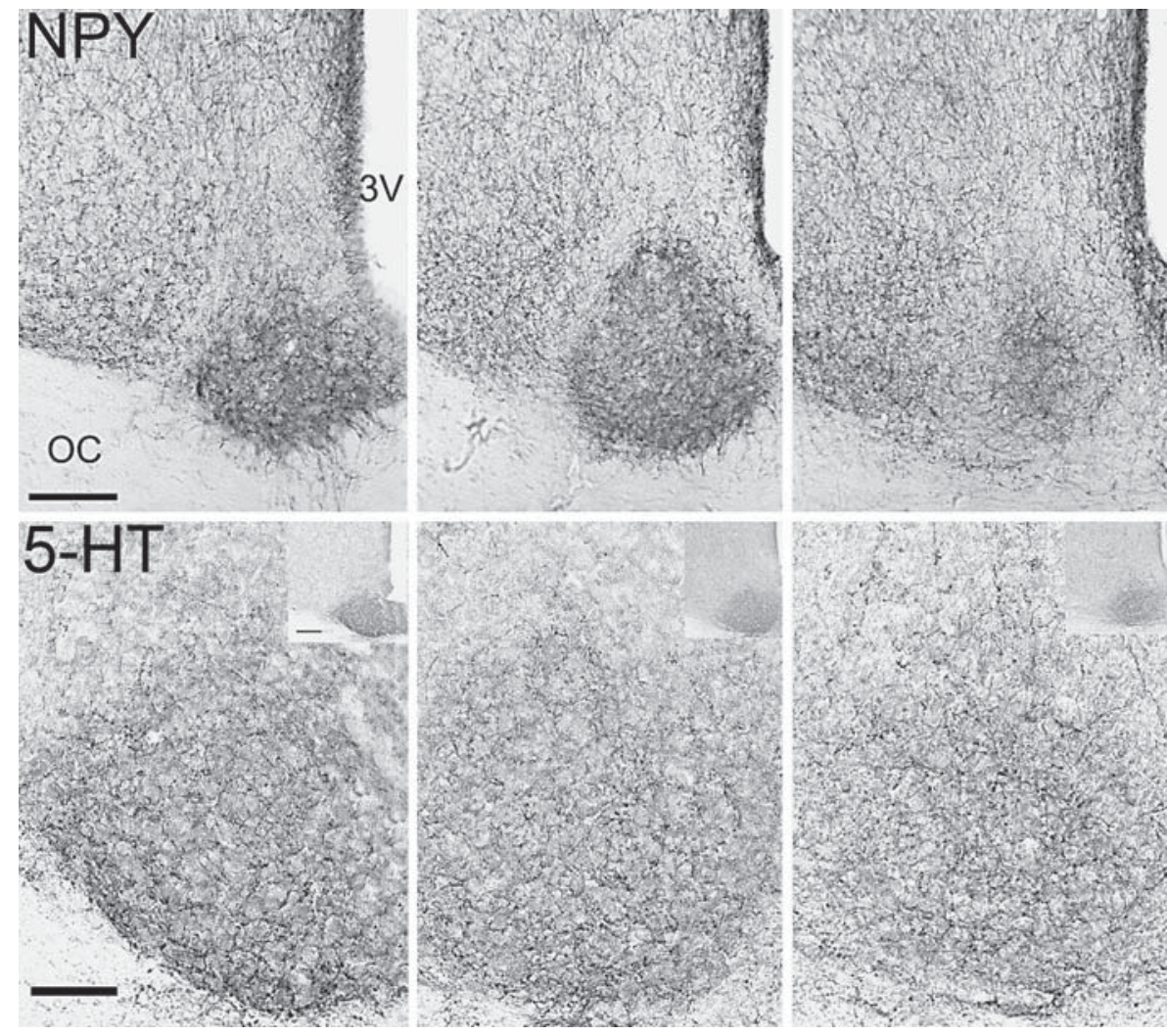

trated in the ventral aspect of the nucleus but also extended dorsally well beyond where VIP-ir cells were seen; (fig. 2, 3, 6). NPY-ir fibers, however, were conspicuously absent in the outer-most region of the nucleus, which appeared as something of a halo encircling the area of labeled fibers (fig. 3, 6). In the caudal SCN, NPY-ir fibers were concentrated within a central area of the nucleus encircled by the surrounding area where few labeled fibers were seen.

At the level of the caudal SCN some NPY-ir fibers were present between the two nuclei, within the optic chiasm ventral to them and in the peri-SCN area, particularly its dorsolateral aspect. Many NPY-ir fibers extended laterally between the SCN and the SON. NPY was also present in cells and fibers in the PVN.

\section{Serotonin}

Fine caliber 5-HT-ir fibers were present from the rostral to the caudal pole of the SCN and were somewhat more concentrated in the ventral portion of the nucleus (fig. 3, 6). Some 5-HT-ir fibers were also present in the surrounding hypothalamus and in the optic chiasm ventral to the SCN.

The SCN of Nocturnal and Diurnal Acomys

\section{Discussion}

\section{Basic Structure of the SCN}

Overall, based on cresyl violet-stained sections and on immunohistochemical analyses, the SCN appears to be very similar in A. russatus and A. cahirinus, and the basic cell phenotypes and inputs to the nucleus in these two species have been seen in a wide variety of others [Moore et al., 2002; Morin et al., 2006]. Cells within the SCN were smaller and more densely packed than in surrounding tissue and the nucleus, which appeared as a teardrop shape that expanded along the dorso-ventral axis from its rostral to its caudal extent. Another conspicuous difference from rostral to caudal poles was that the third ventricle extended completely between the two nuclei to the optic chiasm rostrally, whereas in caudal regions it only reached the level of the most dorsal portions of the two nuclei which were thus in more direct contact with each other along the full length of their medial aspects.

One unusual characteristic of the SCN of spiny mice was that some cells phenotypically identical to those within it were actually separate from it, embedded with- 
in the optic chiasm ventral to it (fig. 2, 3, 5). Processes immunoreactive for VP, VIP and GRP appeared to project from these cells through the chiasm and into the SCN. We have not seen reports of this feature in other species. Developmental processes responsible for the differences in location of the populations of cells within the SCN and within the optic chiasm, respectively, are unclear, but could involve two waves of cell birth or of cell migration.

\section{Organization of Cell Bodies within the SCN}

Vasopressin, the first peptide described in the SCN [Vandesande et al., 1975], has been found in this nucleus of almost all mammals examined to date, which includes a considerable number of species [Sofroniew and Weindl, 1980; Card and Moore, 1984; van den Pol and Tsujimoto, 1985; Cassone et al., 1988; Reuss et al., 1989; Smale et al., 1991; Moore, 1993; Goel et al., 1999]; however, it should be noted that VP is not seen in the SCN of some species, such as the mink [Mustela vison; Bonnefond et al., 1994], the musk shrew [Suncus murinus; Tokunaga et al., 1992] and the naked mole-rat [Heterocephalus glaber; Rosen et al., 2007]. At mid-levels of the Acomys SCN, VP-ir cells were most concentrated in an arc that extended across the dorso-medial portion of the nucleus and continued through the full extent of the medial SCN; in the caudal regions the arc was more limited, as the cells were not present in the lateral portion of the dorsal SCN (fig. 2). The main features of this general pattern are similar to those seen in many species. In nocturnal rodents VP cells have been shown to have rhythms in both electrical activity and in expression of core clock genes [Antle and Silver, 2005].

The ventral portion of the Acomys SCN contained two relatively distinct regions distinguishable on the basis of neuropeptides concentrated within them, as is the case in the SCN of mice [Abrahamson and Moore, 2001], hamsters [Morin et al., 1992; Silver et al., 1996], ground squirrels [Smale et al., 1991] and grass rats [Smale and Boverhof, 1999; Mahoney et al., 2000]. The most ventral aspect of the Acomys SCN contained cells immunopositive for VIP, whereas CalB-ir cells were most concentrated immediately dorsal to them. VIP, the second peptide to be identified in the SCN [Samson et al., 1979], is to our knowledge present in all mammals that have been examined, and this includes a considerable number of species representing numerous orders [Sims et al., 1980; Card and Moore, 1984; Antonopoulos et al., 1987; Cassone et al., 1988; Reuss et al., 1989; Tillet et al., 1989, 1994; Smale et al., 1991; Tokunaga et al., 1992; Moore, 1993; Mikkelsen and Fahrenkrug, 1994; Martinet et al., 1995; Goel et al., 1999; Smale and Boverhof, 1999; Negroni et al., 2003]. These cells are typically, but not always, concentrated in a region of the SCN separate from that containing VP-ir cells. For example, these two populations of cells overlap completely in the SCN of sheep [Tillet et al., 1989] and of some species of opossum [Cassone et al., 1988]. In nocturnal rodents VIP exhibits a daily rhythm within the SCN and VIP cells appear to transmit photic information essential for entrainment to the intrinsically oscillatory cells of the shell [Maywood et al., 2006]. The fact that this peptide appears to be present in the SCN of all mammals, including Acomys, suggests that VIP was present in a common ancestor and provides further support for this model whereby it is essential for entrainment, a function that is universal.

Cells containing CalB-ir were most concentrated in the central portion of the Acomys SCN, extending from the rostral to caudal ends of the nucleus, surrounded by the regions containing VP-ir and VIP-ir cells, respectively (fig. 3,5 ). The distribution of CalB cells varies somewhat across species, and CalB is not present in the SCN of all species. It is seen throughout the SCN of marmosets [Costa and Britto, 1997] and Cryptomys [Negroni et al., 2003], in the central SCN of humans [Mai et al., 1991] and in the peripheral portions of the nucleus in rats [Celio, 1990]. Reports of the distribution of CalB in the SCN of the mouse have been somewhat inconsistent [Abrahamson and Moore, 2001; Morin et al., 2006]. Although in hamsters CalB-expressing cells lack rhythmic electrical activity [Jobst and Allen, 2002], lesions of this sub-region suggest that it is essential for normally functioning circadian rhythms in behavior [Kriegsfeld et al., 2004]. It is not yet clear if this would be the case in other species, such as Acomys.

Relatively small populations of GRP-ir cells were present in the Acomys SCN where they were in an area overlapping both that of VIP-ir cells and that of CalB-ir cells. As with VIP, GRP has been detected in the SCN of all species that have been examined [Roth et al., 1982; Panula et al., 1984; van den Pol, 1986; Mikkelsen et al., 1991; Martinet et al., 1995; Smale and Boverhof, 1999; Abrahamson and Moore, 2001; Moore et al., 2002; Negroni et al., 2003]. The presence of these cells in the Acomys SCN further reinforces the view that this peptide performs a function that is universal and essential for normal patterns of rhythmicity. It has been suggested that this involves modulation of responses of other SCN cells to light as well as communication among different populations of SCN cells [Antle and Silver, 2005]. 
Inputs to the SCN: NPY and 5-HT

Fibers immunoreactive for NPY appear to be present in the SCN of all of the many mammals that have been examined [Card and Moore, 1984; Smith et al., 1985; Ueda et al., 1986; Cassone et al., 1988; Reuss et al., 1989; Bons et al., 1990; Smale et al., 1991; Moore, 1993]. The SCN of Acomys contained fibers and terminals with immunoreactive NPY (fig. 3, 6). From the rostral through mid-levels of the SCN these fine caliber NPY-labeled fibers were most concentrated in the ventral half of the SCN across an area overlapping those of both CalB- and VIP-ir cells. In the caudal sections, however, NPY fibers were more clustered in the central region of the nucleus. NPY-ir fibers were conspicuously absent in the area where VP-ir cells were most concentrated. These fibers are likely to arise from cells in the IGL, as is the case in other diurnal and nocturnal species [e.g., hamsters, Card and Moore, 1984; A. niloticus, Smale et al., 2001], and might convey non-photic signals to the SCN [Yannielli and Harrington, 2004].

5-HT-ir fibers were present in the SCN all along its rostro-caudal axis and their distribution overlapped that of NPY but was not identical to it (fig. 3, 6). They were most highly concentrated in the furthest ventral aspect of the nucleus beyond which their density progressively decreased. There was no sharp boundary between the areas in which they were most and least concentrated, as was the case for NPY (fig. 3, 6). In species in which the function of 5-HT inputs to the SCN has been examined experimentally, they appear to play roles in the modulation of photic influences on the SCN and perhaps the mediation of non-photic effects on the circadian system [Yannielli and Harrington, 2004]. Interestingly, this role appears to be different in nocturnal and at least one diurnal species [Cuesta et al., 2008], suggesting that the 5-HT inputs seen here in both species of spiny mice might have a different influence on their rhythms. The spiny mice could represent an ideal system with which to test the generality of the relationships between 5-HT function and rhythms in day- and night-active animals.

\section{Peptidergic Outflow from the SCN}

In both species of Acomys there was considerable overlap between fibers containing VP-ir, VIP-ir and GRP-ir as they extended outward from the SCN, but there were also some differences. All of these peptides were seen within fibers exiting the SCN dorsally to the PVN, and in the case of VIP and VP some of these appeared to continue to the PVT. These three peptides were also seen in fibers that extended caudally into the full subparaven- tricular area and in fibers that fanned out in a rostral direction into the POA and the AVPV. Fibers containing VP-ir, VIP-ir and GRP-ir also extended laterally from the SCN adjacent to the optic tract to the SON. Relative densities of fibers containing these three different peptides in different areas surrounding the SCN were somewhat variable. For example, VIP-ir fibers formed two distinct tracts in the sub-PVN zone, but VP-ir axons in that area were evenly distributed across the full extent of the medio-lateral axis of the sub-PVN area. In addition, some GRP-ir fibers branched off from that primary tract to fan out in a lateral direction, reaching parts of the POA where neither VIP- nor VP-labeled fibers were seen. Overall, these patterns suggest that there is considerable convergence of different peptidergic signaling peptides in many regions but that the balance of inputs from these different populations might be somewhat variable, and in one area cells possibly receive input from GRP but not VIP or VP cells.

\section{Sub-Compartments of the SCN}

One issue that the current data can influence involves the best way of thinking and communicating about regional differences within the SCN more generally. As noted above, when characterizing the substructure of the SCN, the tradition, derived initially from work on rats and hamsters, has been to focus on major differences between two regions described by Moore et al. [2002] as a core and a shell, respectively. This distinction is based primarily on the distribution of SCN cells containing VIP, GRP and VP, and fibers containing serotonin and NPY, and inputs from the retina [Card and Moore, 1984; Abrahamson and Moore, 2001; Moore et al., 2002]. More recently, Morin et al. [2006] have argued that SCN organization is more complex and that 'oversimplification may hinder rather than facilitate understanding' of SCN structure-function relationships. These authors use triple labeling techniques to very directly compare distributions of inputs to the SCN and cells of different phenotypes within it and show that, indeed, the distinction between core and shell overlooks many features of SCN anatomy in rats and mice. Recent functional data also support the notion that a simple core-shell distinction might neglect important aspects of SCN function, as subregions of the core operate in very different ways [Antle and Silver, 2005] and functional properties of cells can vary along a spatial gradient extending from ventral to dorsal SCN and not be restricted by traditional boundaries [Davidson et al., 2009]. There might, however, be some value in communicating certain features of the SCN in 
broad strokes. Our analysis of the SCN of golden and common spiny mice suggests that in these species a 'tripartite' distinction among sub-regions of the SCN, based on the distributions of cells of different phenotypes, might be most useful. Specifically, although there is some overlap, cells containing VIP-ir, VP-ir and CalB-ir, respectively, are most concentrated within three quite different sub-regions that together cover the entire SCN. It is not entirely clear what terms would be most appropriate to refer to these areas, although one might describe them as a 'core', containing VIP-ir cells, a 'central subnucleus' [see Morin et al., 2006] with CalB-ir cells and a 'shell' with VP-ir cells. A similar tri-partite characterization might also be the best way to describe the organization of the SCN of hamsters, ground squirrels and grass rats. Terminology currently used to describe the hamster SCN can be confusing, as the term 'core' is used sometimes to refer to a VIP-containing region and other times the central sub-nucleus in which CalB and substance P are present, but VIP is all but absent. Cells in these two areas are functionally quite different, which seems likely to be the case in spiny mice and other species as well.

Although the terminology used here nicely describes three complementary sub-compartments that together constitute the SCN as a whole, the fact that some other cell types, as well as inputs to the SCN, extend into more than one of these regions needs to be kept in mind. In spiny mice this is the case for GRP-ir cells and also for the inputs described here. For example, 5-HT-ir fibers were most concentrated in the lateral portions of both core and shell, and NPY-ir fibers filled the core and the central sub-nucleus of the rostral SCN, and only the central subnucleus in the caudal SCN (fig. 6).

\section{Conclusions}

Beyond the general issues pertaining to interspecific differences in SCN structure, the central conclusion that emerges more directly from the present study is that several basic features of the substructure of the SCN are indistinguishable in golden and common spiny mice, two very closely related species whose rhythms differ in fundamental ways. It is important to note, however, that behavioral differences could still be driven by characteristics of SCN anatomy that we did not assess; differences might, for example, be revealed with quantitative analyses of phenotypically distinct cell populations, or of inputs to different sub-regions. Furthermore, it remains possible that the behavioral differences between these species could emerge from functional differences within phenotypically identical cell populations or cell populations we did not examine here. The current data on the basic organization of the SCN and the area around it sets the stage for future studies aimed at unraveling functional characteristics that might account for species differences in behavioral and other rhythms.

\section{Acknowledgements}

This work was funded by BSF grants (2003048 and 2005522), and a Lev Zion fellowship to Rotem Cohen, and MH 53433 from NIMH. We are grateful to Dr. Lily Yan for her comments on an earlier draft of the manuscript and to Dr. Antonio A. Nunez for helpful suggestions as the work was being conducted. Also, I would like to thank Alex and Jessica for all their help.

\section{References}

-Abrahamson EE, Moore RY (2001) Suprachiasmatic nucleus in the mouse: retinal innervation, intrinsic organization and efferent projections. Brain Res 916:172-191.

-Antle MC, Silver R (2005) Orchestrating time: arrangements of the brain circadian clock. Trends Neurosci 28:145-151.

Antonopoulos J, Papadopoulos GC, Karamanlidis AN, Parnavelas JG, Dinopoulos A, Michaloudi H (1987) VIP- and CCK-like-immunoreactive neurons in the hedgehog (Erinaceus europaeus) and sheep (Ovis aries) brain. J Comp Neurol 263:290-307.
Bonnefond C, Peytevin J, Martinet L (1994) The suprachiasmatic nuclei of the mink, Mustela vision, lack parvocellular vasopressinergic neurons: an in situ hybridization and dual immunohistochemical study. In: Advances in Pineal Research, 8th Ed (Moller M, Pevet P, eds), pp 69-75. London: John Libbey and Company Ltd.

Bons N, Mestre N, Petter A, Danger JM, Pelletier G, Vaudry H (1990) Localization and characterization of neuropeptide $\mathrm{Y}$ in the brain of Microcebus murinus (Primate, Lemurian). J Comp Neurol 298:343-361.

-Camerson G, Spencer S (1981) Sigmodon hispidus. Mamm Species 158:1-9.
Card JP, Moore RY (1984) The suprachiasmatic nucleus of the golden-hamster - immunohistochemical analysis of cell and fiber distribution. Neuroscience 13:415-431.

Cassone VM, Speh JC, Card JP, Moore RY (1988) Comparative anatomy of the mammalian hypothalamic suprachiasmatic nucleus. J Biol Rhythms 3:71-91.

Cavalcante JS, Alves AS, Costa MS, Britto LR (2002) Differential distribution of afferents containing serotonin and neuropeptide $\mathrm{Y}$ within the marmoset suprachiasmatic nucleus. Brain Res 927:200-203. 
Celio MR (1990) Calbindin D-28k and parvalbumin in the rat nervous system. Neuroscience 35:375-475.

-Chaplin G (2004) Geographic distribution of environmental factors influencing human skin coloration. Am J Phys Anthropol 125:292302.

-Cohen R, Kronfeld-Schor N (2006) Individual variability and photic entrainment of circadian rhythms in golden spiny mice. Physiol Behav 87:563-574.

-Costa MS, Britto LR (1997) Calbindin immunoreactivity delineates the circadian visual centers of the brain of the common marmoset (Callithrix jacchus). Brain Res Bull 43: 369-373.

-Cuesta M, Mendoza J, Clesse D, Pevet P, Challet E (2008) Serotonergic activation potentiates light resetting of the main circadian clock and alters clock gene expression in a diurnal rodent. Exp Neurol 210:501-513.

-Davidson AJ, Castanon-Cervantes O, Leise TL, Molyneux PC, Harrington ME (2009) Visualizing jet lag in the mouse suprachiasmatic nucleus and peripheral circadian timing system. Eur J Neurosci 29:171-180.

-Elvert R, Kronfeld-Schor N, Dayan T, Haim A, Zisapel N, Heldmaier G (1999) Telemetric field studies of body temperature and activity rhythms of Acomys russatus and A. cahirinus in the Judean Desert of Israel. Oecologia 119:482-492.

Goel N, Lee TM, Smale L (1999) Suprachiasmatic nucleus and intergeniculate leaflet in the diurnal rodent Octodon degus: retinal projections and immunocytochemical characterization. Neuroscience 92:1491-1509.

-Gutman R, Dayan T (2005) Temporal partitioning: an experiment with two species of spiny mice. Ecology 86:164-173.

-Hagenauer MH, Lee TM (2008) Circadian organization of the diurnal Caviomorph rodent, Octodon degus. Biol Rhythm Res 39:269289.

Haim A, Borut A (1975) Size and activity of a cold resistant population of the golden spiny mouse (Acomys russatus: Muridae). Mammalia 39:605-612.

-Hoogenboom I, Daan S, Dallinga JM, Schoenmakers M (1984) Seasonal change in the daily timing of behaviour of the common vole, Microtus arvalis. Oecologia 61:18-31.

-Jablonski N (2004) The evolution of human skin and skin color. Annu Rev Anthropol 33:585623.

-Jiao YY, Lee TM, Rusak B (1999) Photic responses of suprachiasmatic area neurons in diurnal degus (Octodon degus) and nocturnal rats (Rattus norvegicus). Brain Res 817:93103.

-Jobst EE, Allen CN (2002) Calbindin neurons in the hamster suprachiasmatic nucleus do not exhibit a circadian variation in spontaneous firing rate. Eur J Neurosci 16:2469-2474.
Johnston PG, Zucker I (1983) Lability and diversity of circadian rhythms of cotton rats Sigmodon hispidus. Am J Physiol 244:R338R346.

Kalsbeek A, Verhagen LA, Schalij I, Foppen E, Saboureau M, Bothorel B, Buijs RM, Pevet P (2008) Opposite actions of hypothalamic vasopressin on circadian corticosterone rhythm in nocturnal versus diurnal species. Eur J Neurosci 27:818-827.

Klein DC, Moore RY, Reppert SM (1991) Suprachiasmatic Nucleus: The Mind's Clock. New York: Oxford University Press.

Koskela TK, Reiss GR, Brubaker RF, Ellefson RD (1989) Is the high-concentration of ascorbicacid in the eye an adaptation to intense solar irradiation. Invest Ophthalmol Vis Sci 30: 2265-2267.

Krajnak K, Dickenson L, Lee TM (1997) The induction of Fos-like proteins in the suprachiasmatic nuclei and intergeniculate leaflet by light pulses in degus (Octodon degus) and rats. J Biol Rhythms 12:401-412.

Kriegsfeld LJ, LeSauter J, Silver R (2004) Targeted microlesions reveal novel organization of the hamster suprachiasmatic nucleus. J Neurosci 24:2449-2457.

Kronfeld-Schor N, Dayan T (2003) Partitioning of time as an ecological resource. Annu Rev Ecol Evol Syst 34:153-181.

Kronfeld-Schor N, Dayan T (2008) Activity patterns of rodents: the physiological ecology of biological rhythms. Biol Rhythm Res 39: 193-211.

Kronfeld-Schor N, Dayan T, Elvert R, Haim A, Zisapel N, Heldmaier G (2001a) On the use of the time axis for ecological separation: diel rhythms as an evolutionary constraint. Am Nat 158:451-457.

Kronfeld-Schor N, Dayan T, Jones ME, Kremer I, Mandelik Y, Wollberg M, Yassur Y, Gaton DD (2001c) Retinal structure and foraging microhabitat use of the golden spiny mouse (Acomys russatus). J Mammal 82:1016-1025.

Kronfeld-Schor N, Dayan T, Zisapel N, Haim A (1994) Co-existing populations of Acomys cahirinus and A. russatus: a preliminary report. Isr J Zool 40:177-183.

-Kronfeld-Schor N, Haim A, Dayan T, Zisapel N, Klingenspor M, Heldmaier G (2000) Seasonal thermogenic acclimation of diurnally and nocturnally active desert spiny mice. Physiol Biochem Zool 73:37-44.

Kronfeld-Schor N, Shargal E, Haim A, Dayan T, Zisapel N, Heldmaier G (2001b) Temporal partitioning among diurnally and nocturnally active desert spiny mice: energy and water turnover costs. J Therm Biol 26:139142.

Levy O, Dayan T, Kronfeld-Schor N (2007) The relationship between the golden spiny mouse circadian system and its diurnal activity: an experimental field enclosures and laboratory study. Chronobiol Int 24:599-613.

Li X, Gilbert J, Davis FC (2005) Disruption of masking by hypothalamic lesions in Syrian hamsters. J Comp Physiol A 191:23-30.
Mahoney MM, Nunez AA, Smale L (2000) Calbindin and Fos within the suprachiasmatic nucleus and adjacent hypothalamus of Arvicanthis niloticus and Rattus norvegicus. Neuroscience 99:565-575.

Mai JK, Kedziora O, Teckhaus L, Sofroniew MV (1991) Evidence for subdivisions in the human suprachiasmatic nucleus. J Comp Neurol 305:508-525.

Martinet L, Bonnefond C, Peytevin J, Monnerie R, Marcilloux JC (1995) Vasoactive intestinal polypeptide in the suprachiasmatic nucleus of the mink (Mustela vison) could play a key role in photic induction. J Neuroendocrinol 7:69-79.

Maywood ES, Reddy AB, Wong GKY, O’Neill JS, O'Brien JA, McMahon DG, Harmar AJ, Okamura H, Hastings MH (2006) Synchronization and maintenance of timekeeping in suprachiasmatic circadian clock cells by neuropeptidergic signaling. Curr Biol 16: 599-605.

Mendelson H, Yom-Tov Y (1999) Mammalia of Israel. Jerusalem, Israel: The Israel Acadamy of Sciences and Humanities.

Mikkelsen JD, Fahrenkrug J (1994) Concentrations and distribution of vasoactive intestinal peptide (VIP), peptide histidine isoleucine (PHI) and peptide histidine valine (PHV) in the cerebral cortex and the suprachiasmatic nucleus of the mouse. Brain Res 656:95-107.

Mikkelsen JD, Larsen PJ, O’Hare MM, Wiegand SJ (1991) Gastrin releasing peptide in the rat suprachiasmatic nucleus: an immunohistochemical, chromatographic and radioimmunological study. Neuroscience 40:55-66.

-Moore RY (1993) Organization of the Primate Circadian System. J Biol Rhythms 8:S3-S9.

-Moore RY, Speh JC, Leak RK (2002) Suprachiasmatic nucleus organization. Cell Tissue Res 309:89-98.

Morin LP, Blanchard J, Moore RY (1992) Intergeniculate leaflet and suprachiasmatic nucleus organization and connections in the golden hamster. Vis Neurosci 8:219-230.

Morin LP, Shivers KY, Blanchard JH, Muscat L (2006) Complex organization of mouse and rat suprachiasmatic nucleus. Neuroscience 137:1285-1297.

Mrosovsky N (1999) Masking: History, definitions, and measurement. Chronobiol Int 16: 415-429.

-Mrosovsky N, Hattar S (2005) Diurnal mice (Mus musculus) and other examples of temporal niche switching. J Comp Physiol A 191: 1011-1024.

Negroni J, Bennett NC, Cooper HM (2003) Organization of the circadian system in the subterranean mole rat, Cryptomys hottentotus (Bathyergidae). Brain Res 967:48-62.

Novak CM, Ehlen JC, Huhman KL, Albers HE (2004) GABA(B) receptor activation in the suprachiasmatic nucleus of diurnal and nocturnal rodents. Brain Res Bull 63:531-535. 
Panula P, Yang HY, Costa E (1984) Comparative distribution of bombesin/GRP- and substance-P-like immunoreactivities in rat hypothalamus. J Comp Neurol 224:606-617.

-Pinato L, Allemandi W, Abe LK, Frazao R, CruzRizzolo RJ, Cavalcante JS, Costa MS, Nogueira MI (2007) A comparative study of cytoarchitecture and serotonergic afferents in the suprachiasmatic nucleus of primates (Cebus apella and Callithrix jacchus) and rats (Wistar and Long Evans strains). Brain Res 1149: 101-110.

Redlin U (2001) Neural basis and biological function of masking by light in mammals: suppression of melatonin and locomotor activity. Chronobiol Int 18:737-758.

-Redlin U, Mrosovsky N (2004) Nocturnal activity in a diurnal rodent (Arvicanthis niloticus): the importance of masking. J Biol Rhythms 19:58-67.

Reuss S, Hurlbut EC, Speh JC, Moore RY (1989) Immunohistochemical evidence for the presence of neuropeptides in the hypothalamic suprachiasmatic nucleus of ground squirrels. Anat Rec 225:341-346.

-Rosen GJ, De Vries GJ, Goldman SL, Goldman BD, Forger NG (2007) Distribution of vasopressin in the brain of the eusocial naked mole-rat. J Comp Neurol 500:1093-1105.

Roth KA, Weber E, Barchas JD (1982) Distribution of gastrin releasing peptide-bombesinlike immunostaining in rat brain. Brain Res 251:277-282.

Rowsemitt C, Petterborg LJ, Claypool LE, Hoppensteadt FC, Negus NC, Berger PJ (1982) Photoperiodic induction of diurnal locomotor-activity in Microtus-Montanus, the montane vole. Can J Zool/Rev Can Zool 60: 2798-2803.

Samson WK, Said SI, McCann SM (1979) Radioimmunologic localization of vasoactive intestinal polypeptide in hypothalamic and extrahypothalamic sites in the rat brain. Neurosci Lett 12:265-269.
- Scott DM, Dunstone N (2000) Environmental determinants of the composition of desertliving rodent communities in the north-east Badia region of Jordan. J Zool 251:481-494.

Shkolnik A (1966) Studies in the comparative biology of Israel's two species of spiny mice (genus Acomys). PhD thesis (in Hebrew, English summary) Hebrew Univ., Jerusalem.

Shkolnik A (1971) Diurnal activity in a small desert rodent. Int J Biometeorol 15:115-120.

- Silver R, Romero MT, Besmer HR, Leak R, Nunez JM, LeSauter J (1996) Calbindin-D28K cells in the hamster SCN express light-induced Fos. Neuroreport 7:1224-1228.

-Sims KB, Hoffman DL, Said SI, Zimmerman EA (1980) Vasoactive intestinal polypeptide (VIP) in mouse and rat brain: an immunocytochemical study. Brain Res 186:165-183.

- Smale L, Boverhof J (1999) The suprachiasmatic nucleus and intergeniculate leaflet of Arvicanthis niloticus, a diurnal murid rodent from East Africa. J Comp Neurol 403:190208.

-Smale L, Blanchard J, Moore RY, Morin LP (1991) Immunocytochemical characterization of the suprachiasmatic nucleus and the intergeniculate leaflet in the diurnal ground squirrel, Spermophilus lateralis. Brain Res 563: 77-86.

Smale L, McElhinny T, Nixon J, Gubik B, Rose S (2001) Patterns of wheel running are related to Fos expression in neuropeptide-Y-containing neurons in the intergeniculate leaflet of Arvicanthis niloticus. J Biol Rhythms 16: 163-172.

- Smale L, Nunez AA, Schwartz MD (2008) Rhythms in a diurnal brain. Biol Rhythm Res 39:305-318.

-Smith Y, Parent A, Kerkerian L, Pelletier G (1985) Distribution of neuropeptide Y immunoreactivity in the basal forebrain and upper brainstem of the squirrel monkey (Saimiri sciureus). J Comp Neurol 236:71-89.

Sofroniew MV, Weindl A (1980) Identification of parvocellular vasopressin and neurophysin neurons in the suprachiasmatic nucleus of a variety of mammals including primates. J Comp Neurol 193:659-675.
Tillet Y, Caldani M, Tramu G (1989) Immunohistochemical characterization of the sheep suprachiasmatic nucleus. J Chem Neuroanat 2:215-226.

Tillet Y, Thibault J, Krieger M (1994) Aromatic L-amino acid decarboxylase immunohistochemistry in the suprachiasmatic nucleus of the sheep. Comparison with tyrosine hydroxylase immunohistochemistry. Brain Res 648:319-323.

Tokunaga A, Ono K, Kondo S, Tanaka H, Kurose K, Nagai H (1992) Retinal projections in the house musk shrew, Suncus murinus, as determined by anterograde transport of WGAHRP. Brain Behav Evol 40:321-329.

- Tournier BB, Dardente H, Vuillez P, Pevet P, Challet E (2007) Expression of Tgfalpha in the suprachiasmatic nuclei of nocturnal and diurnal rodents. Neuroscience 145:11381143.

Ueda S, Kawata M, Sano Y (1986) Identification of neuropeptide $\mathrm{Y}$ immunoreactivity in the suprachiasmatic nucleus and the lateral geniculate nucleus of some mammals. Neurosci Lett 68:7-10.

van den Pol AN (1986) Gamma-aminobutyrate, gastrin releasing peptide, serotonin, somatostatin, and vasopressin: ultrastructural immunocytochemical localization in presynaptic axons in the suprachiasmatic nucleus. Neuroscience 17:643-659.

van den Pol AN, Tsujimoto KL (1985) Neurotransmitters of the hypothalamic suprachiasmatic nucleus - immunocytochemical analysis of 25 neuronal antigens. Neuroscience 15:1049-1086.

Vandesande F, Dierickx K, DeMey J (1975) Identification of the vasopressin-neurophysin producing neurons of the rat suprachiasmatic nuclei. Cell Tissue Res 156:377-380.

Weber ET, Hohn VM (2005) Circadian activity rhythms in the spiny mouse, Acomys cahirinus. Physiol Behav 86:427-433.

Yannielli P, Harrington ME (2004) Let there be 'more' light: enhancement of light actions on the circadian system through non-photic pathways. Prog Neurobiol 74:59-76. 